\title{
Prostaglandin release in canine acute haemorrhagic pancreatitis
}

\author{
GEOFFREY GLAZER AND ALAN BENNETT \\ From the Surgical Unit, St Mary's Hospital Medical School, and the Department of Surgery, King's College \\ Hospital Medical School, London
}

SUMMARY Acute haemorrhagic pancreatitis was induced in greyhound dogs by a bile salt/trypsin injection into the main pancreatic duct. Prostaglandin-like activity in the pancreatic venous blood, right atrial blood, and arterial blood was measured by bioassay. Activity rose significantly in the pancreatic venous blood of test dogs but not in controls. Chromatographic analysis of the peritoneal exudate from the dogs with pancreatitis showed high levels of prostaglandin E-like material (mean $43 \mathrm{ng} / \mathrm{ml}$ prostaglandin $\mathrm{E}_{2}$ equivalents). It seems likely that prostaglandins contribute to the induced pancreatitis.

Hypotension and pain in acute pancreatitis have been attributed to hypovolaemia and the release of plasma kinins, but there is evidence of other contributory factors (Ofstad, 1970). Many inflammatory exudates contain prostaglandins (PGs) and these substances can cause hypotension, pain and inflammation. Experiments were therefore designed to measure PG-like activity in dog pancreatic venous blood, the general circulation, and peritoneal exudate after the induction of acute haemorrhagic pancreatitis (AHP).

\section{Methods}

Adult greyhound dogs, anaesthetized with sodium pentobarbitone $(25 \mathrm{mg} / \mathrm{kg}$ intravenously), were intubated and allowed to breath spontaneously. A femoral artery cannula (30 cm long, $2.76 \mathrm{~mm}$ O.D.) was passed into the abdominal aorta and used to collect arterial blood and to record blood pressure and heart rate continuously (SE Labs. SEM 488 pressure transducer via a SAN-E1 pressure amplifier type 1206 and Watanabe MC-611 multi-channel pen recorder). Mixed venous blood was obtained from the right atrium through a cannula $(30 \mathrm{~cm}$ long, $2.1 \mathrm{~mm}$ O.D.) passed down from the right jugular vein. Pancreatic venous blood was sampled by the method of Poperaitis and Thompson (1969): the abdomen was opened by an upper midline incision, the spleen removed and a polyethylene cannula (30 cm long, $2 \cdot 1 \mathrm{~mm}$ O.D.) passed into the

Received for publication 20 October 1975 portal vein through the splenic vein. Several veins draining into the portal system were ligated (right gastric, right and left gastro-epiploic and inferiopancreatico-duodenal veins), and temporary occlur ding silk cinches were passed around the left gastric vein, mesenteric vein, and portal vein above the tip of the cannula. When these cinches were applied, the blood sampled from the portal vein was derived almost entirely from the pancreas; only a small amount came from the duodenum via the superior pancreatico-duodenal vein.

In four control dogs (mean body weight, $28 \mathrm{~kg}$ ) the lesser and main pancreatic ducts were ligated. In eight test dogs (mean body weight, $27 \mathrm{~kg}$ ), acute haemorrhagic pancreatitis (AHP) was induced by a bile salt/trypsin mixture (Elliot et al., 1958) which contained $4 \%$ sodium taurocholate (ox bile extract; Sigma Chemical Co.) and 75,000 benzyl arginine ethyl ester units of crystalline trypsin (Sigma Chemical Co.) in saline at $37^{\circ} \mathrm{C}$ and $\mathrm{pH} 7.7$ (adjusted with sodium bicarbonate). The lesser pancreatic duct was ligated; a polyethylene cannula $(30 \mathrm{~cm}$ long, $1.3 \mathrm{~mm}$ O.D.) was placed extraduodenally in the main pancreatic duct and $1.5 \mathrm{ml} / \mathrm{kg}$ of the mixture was infused into the pancreas through the cannula at a pressure not exceeding $50 \mathrm{~cm}$ of water. At the end of the infusion the cannula was withdrawn and the main duct ligated.

Throughout the experimental period, saline 80 $\mathrm{ml} / \mathrm{h}$ was infused intravenously. Base-ıine blood samples were taken from the aorta (arterial), portal vein (pancreatic venous), and right atrium (mixed venous) after the preparation was set up, and 
repeated 30 minutes later. Then in the control dogs the pancreatic duct was ligated, and in the test animals pancreatitis was induced. Further blood samples were taken at $0.5,1,2$, and $3 \mathrm{~h}$. Each blood sample was collected in a heparinized tube and after rapidly centrifuging, the plasma was frozen at $-20^{\circ} \mathrm{C}$. Total PG-like activity was extracted within three days (Unger et al., 1971) and assayed biologically on the rat gastric fundus strip in the presence of various drugs to increase selectivity and sensitivity (Bennett et al., 1973). Samples of aortic blood were also taken at similar time intervals for estimation of amylase (Phadebas test: Pharmacia Great Britain Ltd.), haemoglobin, and haematocrit (Coulter Counter, Model S7). In five dogs with pancreatitis a sample of peritoneal exudate from the pancreatic region was obtained at the end of the experiment. These samples were spun to remove red blood cells and then frozen at $-20^{\circ} \mathrm{C}$ until extraction and bioassay of PG-like activity. Chromatographic investigation (Stamford and Unger, 1972) was also carried out on these specimens. There was no exudate in the control group. All dogs were killed by a large dose of sodium pentobarbitone and samples of pancreas from the left lobe, right lobe, and head were obtained for histological examination.

Results were analysed statistically using the Walsh (1949) non-parametric test. The average of the two base-line readings was compared with the subsequent readings during each experiment and each animal served as its own control.

\section{Results}

\section{HISTOLOGY}

None of the control dogs developed any macroscopic or histological changes, whereas all the test dogs showed the macroscopic changes of oedema, congestion, and haemorrhagic areas in the pancreas together with a serosanguinous peritoneal exudate. Histological examination showed oedema, inflammatory cell infiltration, and haemorrhage; these findings confirmed the presence of AHP.

\section{HAEMODYNAMIC DATA}

The dogs in the pancreatitis group developed an acute transitory fall in blood pressure (BP) during the infusion of the bile salt/trypsin mixture into the duct. After this, the blood pressure fell steadily throughout the experiment (mean basal BP, 155 $\mathrm{mmHg}$, falling to $75 \mathrm{mmHg} 3 \mathrm{~h}$ after inducing AHP). In the control group after duct ligation, there was only a slight fall in blood pressure during the experiment (mean basal BP, $145 \mathrm{mmHg} ; 120 \mathrm{mmHg}$ after $3 \mathrm{~h}$ ). Mean heart rate rose from a basal rate of $140 / \mathrm{min}$ to $200 / \mathrm{min} 3 \mathrm{~h}$ after inducing AHP, and a smaller rise occurred in the controls (mean basal heart rate $150 / \mathrm{min}$, rising to $176 / \mathrm{min}$ at $3 \mathrm{~h}$ ). Similar changes have been reported by others in canine AHP (Carey and Rodgers, 1966).

\section{AMYLASE AND HAEMATOLOGICAL DATA}

The changes in blood amylase and haematocrit are depicted in Figs. 1 and 2. Blood amylase rose in all the dogs with pancreatitis $(\mathrm{P}<0.01$ in all measurements). Haemoconcentration occurred in the pancreatitis group, as reflected in the rising haematocrit ( $P<0.01$ in all measurements); these readings were partly masked by replacement of blood with saline, which accounts for the slight fall in haematocrit in the control animals. Haematocrit changes in dogs with AHP paralleled the plasma volume deficits, which Carey and Rodgers (1966) found to be $34 \%$ after $4 \mathrm{~h}$.

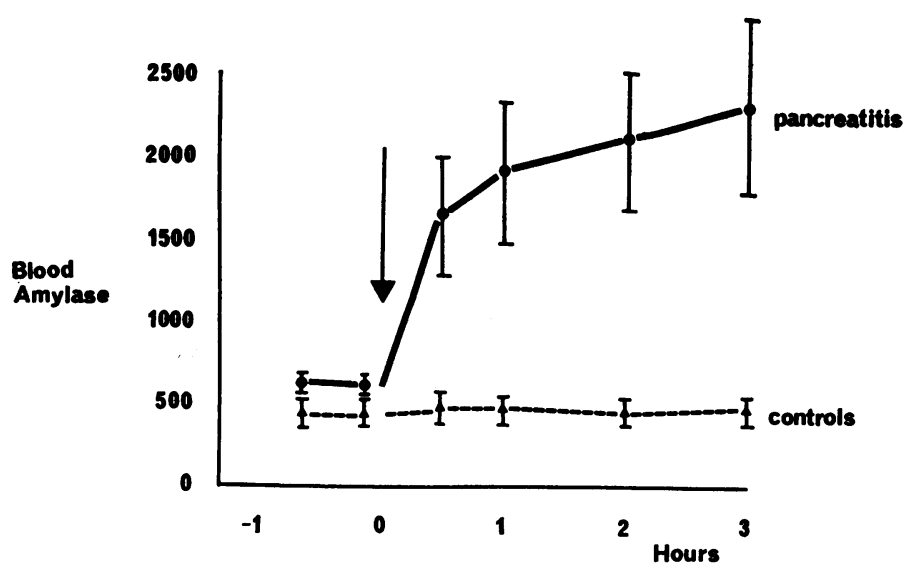

Fig. 1 The level of blood amylase (Somogyi Units $100 \mathrm{ml}$ ) rose in dogs with pancreatitis $(n=8)$ but not in control dogs $(n=4)$. The vertical bars represent $\pm S E(\mathrm{P}<0.01$ at $0 \cdot 5,1,2$, and $3 h)$. (AHP or duct ligation at $0 h$, shown by the arrow.) 


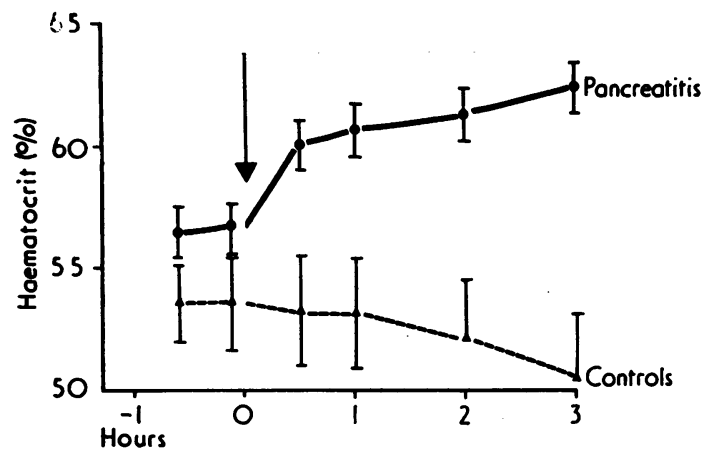

Fig. 2 The haematocrit rose in dogs with pancreatitis $(n=8)$ bur this effect was partly masked by the saline infusion; the fall in haematocrit in control dogs $(n=4)$ was also due to the saline replacement of blood samples. The vertical bars represent $\pm S E(\mathrm{P}<0.01$ at $0.5,1,2$, and $3 h$ ).

\section{PROSTAGLANDIN DATA}

Bioassay after extraction can reliably measure the prostaglandin-like activity in blood. However, as with most techniques, it does not allow firm conclusions on the precise nature of the material, particularly when insufficent is available for chromatography. Hence, reference is made to 'prostaglandin-like material' which has been assayed against pure $\mathrm{PGE}_{2}$.

The mean changes in PG-like activity in the pancreatic venous blood, mixed venous blood (right atrial) and arterial blood, are shown in Figs. 3-5. The level of PG-like material in the pancreatic venous blood of dogs with AHP rose steadily from a mean average basal level of $0.3 \mathrm{ng} / \mathrm{ml} \mathrm{PGE}_{2}$ equivalents to $1.0 \mathrm{ng} / \mathrm{ml}$ at $30 \mathrm{~min}$ and $1.7 \mathrm{ng} / \mathrm{ml}$ at $3 \mathrm{~h}(\mathrm{P}<0.05$ at $30 \mathrm{~min} ; \mathrm{P}<0.01$ at 1,2 and $3 \mathrm{~h})$; controls were unchanged. The levels in mixed venous blood did not change significantly in either group, and, although the mean level of PG-like material in the arterial blood of dogs with AHP was higher than in control dogs, this did not reach statistical significance. However, large amounts of PG-like material occurred in the peritoneal exudates from dogs with AHP (43 $\pm 7 \cdot 2$ (SE) ng/ml PGE 2 equivalents). Chromatographic analysis and susceptibility to alkaline hydrolysis $\left(0 \cdot 1 \mathrm{M} \mathrm{NaOH}, 37^{\circ} \mathrm{C}, 30 \mathrm{~min}\right)$ indicated a PGE compound with traces of other activity in some samples. No peritoneal exudate occurred in the control animals.

\section{Discussion}

This report demonstrates that during the early stages of AHP in the dog, PG-like material is released into the pancreatic venous blood. Furthermore, the peritoneal exudate contains substantial PG-like activity comparable in amount with that found in other inflamed sites, such as the eye (Eakins et al., 1972). It was not possible to characterize the small amounts of material in the blood, but chromatographic analysis and alkaline hydrolysis of extracted peritoneal exudates, showed mainly PGE-like activity. The similar levels in the mixed venous blood of pancreatitis and control dogs probably indicate metabolism of the released material by the liver, and/or dilution by other venous blood. The raised level of PG-like activity in the arterial blood of dogs with pancreatitis was not statistically significant, and the particularly high mean level at $3 \mathrm{~h}$ was due to results from only two of the eight experiments. Perhaps in some dogs with early AHP a trigger mechanism in pancreatitis releases PG-like material from the lungs. Slight mechanical damage to the lungs releases PG-like activity (Piper and Vane, 1971), and 5-hydroxytryptamine or tryptamine can trigger the release of PG-like material from guinea-pig isolated lungs (Alabaster and Bakhle, 1970).

Many vasoactive substances are released in AHP, and are thought to contribute to the shock state by

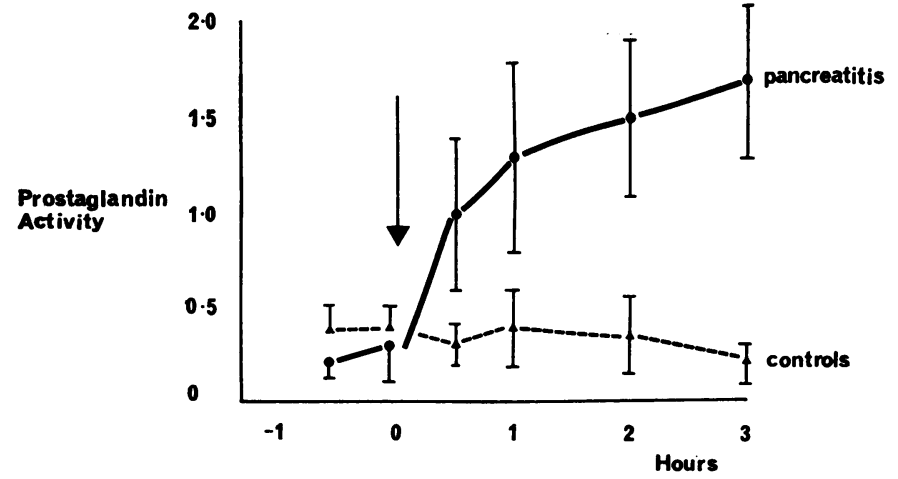

Fig. 3 The mean level of PG-like material increased in the pancreatic venous blood of dogs with pancreatitis $(n=8)$ but not in control dogs $(n=4)$. Results are expressed as $P G E_{2}$ equivalents ( $\mathrm{ng} / \mathrm{ml}$ plasma). The vertical bars represent $\pm S E(\mathrm{P}<0.05$ at 0.5 $h ; \mathrm{P}<0.01$ at 1,2 , and $3 h$ ). 

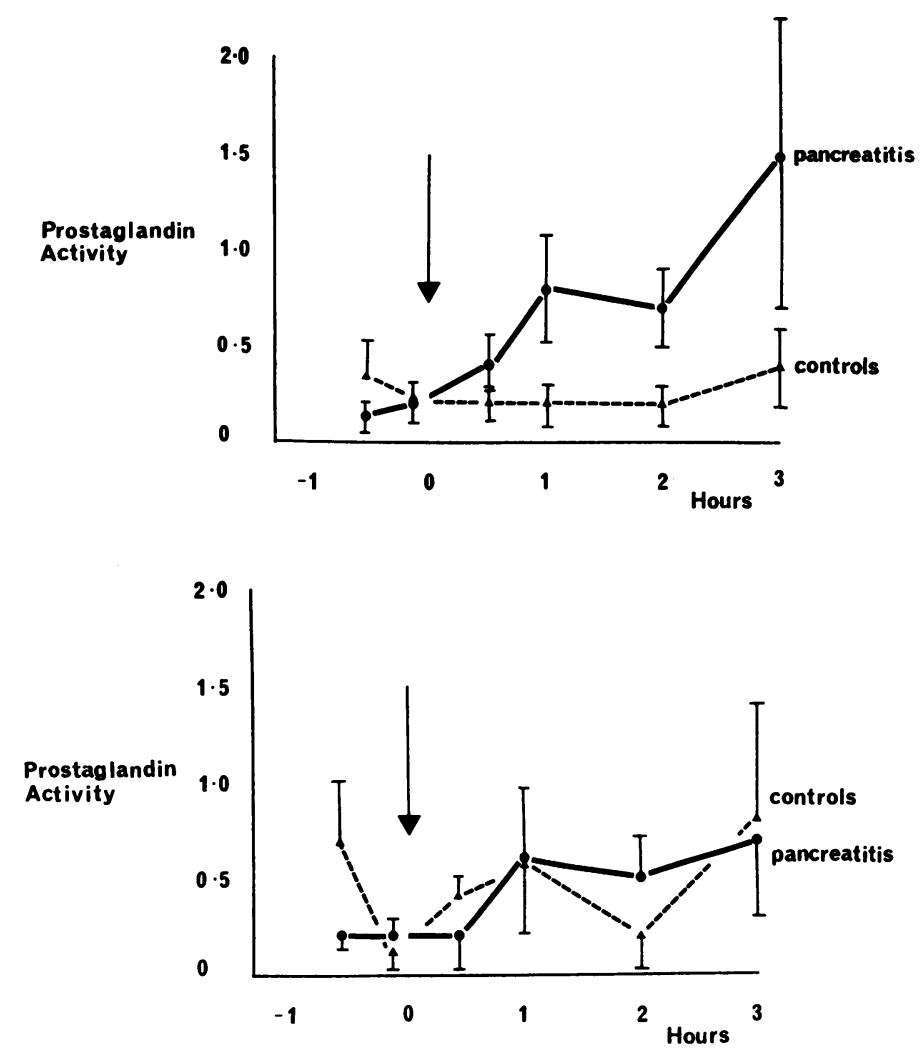

Fig. 4 The mean level of PG-like activity rose in the arterial blood of dogs with pancreatitis $(n=8)$ but this was not statistically significant. The high mean level at $3 h$ was due to results from only two out of eight experiments. There was no change in control dogs $(n=4)$. Results are expressed as $P G E_{2}$ equivalents (ng/ml plasma). The vertical bars represent $\pm S E$.
Fig. 5 The mean level of PG-like activity did not alter significantly in the right atrial (mixed venous) blood of dogs with pancreatitis $(n=6)$ or control dogs $(n=3)$. Results are expressed as $P G E_{2}$ equivalents (ng/ml plasma). The vertical bars represent $\pm S E$. increasing vascular permeability and peritoneal exudation (Katz et al, 1964). Considerable attention has been given to the role of kinins, but other factors may be important (Ofstad, 1970). There is substantial evidence that PGs are involved in the inflammatory response (Vane, 1972), and PGE compounds are also hypotensive and increase vascular permeability (Nakano and McCurdy, 1967). Furthermore, various PGs can potentiate responses in guinea-pig skin to bradykinin, histamine, and allergic inflammatory reactions (Williams and Morley, 1973). $\mathrm{PGE}_{1}$ also potentiates the pain caused by bradykinin and histamine in human skin (Ferreira, 1972), and produces a pain response when injected intraperitoneally in mice (Collier and Schneider, 1972). Substances in the peritoneal exudate in pancreatitis seem important, since improvement is obtained experimentally and clinically after peritoneal lavage (Rosato et al., 1973).

PGs might also exacerbate the pancreatic autodigestive process in pancreatitis by stimulating enzyme production or by reducing pancreatic blood flow. The volume of exocrine secretion during acute pancreatitis is not known, but several drugs used in therapy-for example, anticholinergics, and glucagon-are thought to act by suppressing enzyme production. In the normal dog, $\mathrm{PGE}_{1}$ given intravenously in large doses $(0.5-50 \mu \mathrm{g} / \mathrm{kg})$ increased the pancreatic enzyme output (Rudick et al., 1971), and lower doses of $\mathrm{PGE}_{2}$ or $\mathrm{PGF}_{2_{\alpha}}(0.05-0.4 \mu \mathrm{g} / \mathrm{kg} / \mathrm{min})$ infused into the aorta increased enzyme output and concentration during stimulation with secretin (G. Glazer, unpublished). Blood flow is reduced by $\mathrm{PGE}_{1}$ in the resting dog pancreas (Lefebvre and Luyckx, 1972) and by $\mathrm{PGE}_{2}$ or $\mathrm{PGF}_{2 \alpha}$ in the secreting dog pancreas (G. Glazer, unpublished). As pancreatic vasoconstriction during acute pancreatitis increases tissue anoxia and acinar cell damage, and eventually causes gland necrosis (Goodhead, 1969), local vascular effects of PGs could be important.

We thank Professor H. A. F. Dudley for his advice and help, and Mrs C. F. Gradidge, Mrs B. Raja, Mrs S. Sriharan, and Mr I. F. Stamford for excellent technical assistance. This work was supported by a grant from the Joint Standing Research Fund of St Mary's Hospital, London. 


\section{References}

Alabaster, V. A., and Bakhle, Y. S. (1970). The release of biologically active substances from isolated lungs by 5-hydroxytryptamine and tryptamine. British Journal of Pharmacology, 40, 582P-583P.

Bennett, A., Stamford, I. F., and Unger, W. G. (1973). Prostaglandin $E_{8}$ and gastric acid secretion in man. Journal of Physiology, 229, 349-360.

Carey, L. C., and Rodgers, R. E. (1966). Pathophysiologic alterations in experimental pancreatitis. Surgery, 60, 171-178.

Collier, H. O. J., and Schneider, C. (1972). Nociceptive response to prostaglandins and analgesic actions of aspirin and morphine. Nature New Biology, 236, 141-143.

Eakins, K. E., Whitelocke, R. A. F., Perkins, E. S., Bennett, A., and Unger, W. G. (1972). Release of prostaglandins in ocular inflammation in the rabbit. Nature New Biology, 239, 248-249.

Elliott, D. W., Williams, R. D., and Stewart, W. R. C. (1958). The role of trypsin and of bile salts in the pathogenesis of acute pancreatitis. Surgical Forum, 9, 533.

Ferreira, S. H. (1972). Prostaglandins, aspirin-like drugs and analgesia. Nature New Biology, 240, 200-203.

Goodhead, B. (1969). Acute pancreatitis and pancreatic blood flow. Surgery, Gynecology and Obstetrics, 129, 331-340.

Katz, W., Silverstein, M., Kobold, E. E., and Thal, A. P. (1964). Trypsin release, kinin production and shock. Archives of Surgery, 89, 322-331.

Lefebvre, P. J., and Luyckx, A. S. (1972). Effect of prostaglandin $\mathrm{PGE}_{1}$ on blood flow and insulin output of $\mathrm{dog}$ pancreas in situ. Diabetes, 21, (Suppl. 1) 369.

Nakano, J., and McCurdy, J. R. (1967). Cardiovascular effects of prostaglandin $\mathrm{E}_{1}$. Journal of Pharmacology and Experimental Therapeutics, 156, 538-547.

Ofstad, E. (1970). Formation and destruction of plasma kinins during experimental acute hemorrhagic pancreatitis in dogs. Scandinavian Journal of Gastroenterology, 5, Suppl. 5, 1-44.

Piper, P., and Vane, J. (1971). The release of prostaglandins from lung and other tissues. Annals of the New York Academy of Sciences, 180, 363-385.

Popieraitis, A. S., and Thompson, A. G. (1969). The site of bradykinin release in acute experimental pancreatitis. Archives of Surgery, 98, 73-76.

Rosato, E. F., Mullis, W. F., and Rosato, F. E. (1973). Peritoneal lavage therapy in hemorrhagic pancreatitis. Surgery, 74, 106-115.

Rudick, J., Gonda, M., Dreiling, D. A., and Janowitz, H. D. (1971). Effects of prostaglandin $\mathrm{E}_{1}$ on pancreatic exocrine function. Gastroenterology, 60, 272-278.

Stamford, I. F., and Unger, W. G. (1972). Improved purification and chromatography of extracts containing prostaglandins. Journal of Physiology, 225, 4P-5P.

Unger, W. G., Stamford, I. F., and Bennett, A. (1971). Extraction of prostaglandins from human blood. Nature, 233, 336-337.

Vane, J. R. (1972). Prostaglandins in the inflammatory response. In Inflammation: Mechanisms and Control, pp. 261-279. Edited by I. H. Lepow and P. A. Ward. Academic Press: New York.

Walsh, J. E. (1949). Some significance tests for the median which are valid under very general conditions. Annals of Mathematical Statistics, 20, 64-81.

Williams, T. J., and Morley, J. (1973). Prostaglandins as potentiators of increased vascular permeability in inflammation. Nature, 246, 215-217. 